\title{
Sleep and Early Cortical Development
}

\author{
Salome Kurth • Nadja Olini • Reto Huber • \\ Monique LeBourgeois
}

Published online: 3 February 2015

(C) Springer International Publishing AG 2015

\begin{abstract}
Sleep is increasingly recognized as a key process in neurodevelopment. Animal data show that sleep is essential for the maturation of fundamental brain functions, and growing epidemiological findings indicate that children with early sleep disturbance suffer from later cognitive, attentional, and psychosocial problems. Still, major gaps exist in understanding processes underlying links between sleep and neurodevelopment. One challenge is to translate findings from animal research to humans. In this review, we describe parallels and differences in sleep and development of the cortex in humans and animals and discuss emerging questions.
\end{abstract}

Keywords Sleep · Cortical development .

Electroencephalographic recording $\cdot$ Neurodevelopment .

White matter $\cdot$ Function of sleep

This article is part of the Topical Collection on Function of Sleep

S. Kurth $(\bowtie) \cdot$ M. LeBourgeois

Sleep and Development Laboratory, Department of Integrative

Physiology, University of Colorado Boulder, Clare Small Room 114, 354 UCB, Boulder, CO 80309-5003, USA

e-mail: Salome.Kurth@Colorado.EDU

M. LeBourgeois

e-mail: Monique.LeBourgeois@Colorado.EDU

N. Olini $\cdot$ R. Huber

Child Development Center, University Children's Hospital Zurich,

Zurich, Switzerland

N. Olini

e-mail: Nadja.Olini@kispi.uzh.ch

R. Huber

e-mail: Reto.Huber@kispi.uzh.ch

R. Huber

University Clinic for Child and Adolescent Psychiatry, Zurich,

Switzerland

\section{Introduction}

In all species studied so far, measures of sleep regulation and sleep depth undergo dramatic changes throughout development. Sleep electroencephalogram (EEG) in humans and electrocorticogram $(\mathrm{ECoG})$ recordings in animals provide unique in vivo opportunities to observe regional changes in brain activity over the course of postnatal cortical maturation. This article reviews recent literature on the development of sleep and the cortex, highlights parallels and differences between human and animal findings, and discusses emerging fundamental questions in the field.

Development of Sleep

\section{Ontogenesis of Sleep Stages}

Brain activity during sleep undergoes dramatic changes across the life span. The preterm infant EEG is characterized by the alternation between high-amplitude burst "on" periods followed by low-amplitude burst "off" periods (tracé discontinu), which evolves to high-voltage slow-wave activity alternating with low-voltage activity bursts (tracé alternant) shortly after birth [1]. Soon thereafter, rapid-eye-movement (REM)-like sleep (active sleep) appears. In the course of the first years of life, the amount of active sleep diminishes while nonrapid-eye-movement (non-REM)-like sleep (quiet sleep) becomes the predominant state $[2,3]$.

The sleep characteristics and transitions in early animal life are similar to those of humans, including tracé discontinu in fetal macaque hippocampal slices in vitro during the second half of gestation [4] or the discontinuous temporal organization activity patterns in rodents in vivo. Extracellular and patch-clamp recordings of the somatosensory cortex in neonatal rats reveal bursts of activity interspersed with periods of electrical silence [5]. In contrast to the gradual disappearance 
of the tracé discontinu in humans after birth, rats exhibit such periods much longer [1], suggesting that the rat is less mature in comparison to a newborn human infant at term. Indeed, the degree of cerebral cortical maturation of 12-13-day-old rats (postnatal day [P] 12/13) was estimated to correspond to that of a full-term newborn human infant [6]. After the first two postnatal weeks, the rat ECoG becomes characteristic of waking, REM and non-REM sleep [7], and at P17, the three vigilance states are adult like.

\section{Sleep Architecture}

Throughout infancy and early childhood, the most noticeable changes include the gradual consolidation of sleep and waking bouts [8], the intensification of deep sleep slowwave activity (SWA, 1-4.5 Hz, non-REM), and a progressive decrease of REM (active) sleep proportion that reaches adult levels around age 5 years [3]. Similar to humans, rats show a dramatic change in sleep architecture in the first month of life (i.e., pre-puberty), including a decrease in REM sleep and an increase in non-REM sleep [7]. In contrast to humans though, animals (rat, cat, guinea pig) exhibit a decrease in wakefulness throughout the first 2 weeks of life and an increase thereafter [7]. Throughout human as well as animal pubertal development, sleep architecture changes are less pronounced and include an increase in wakefulness and a decrease in both non-REM and REM sleep [9, 10].

The EEG maturity level at birth is different across mammalian species, which is reflected in the amount of REM sleep. For example, while rats are relatively immature compared to humans, guinea pigs are advanced [7]. As a marker of developmental status, maturity may be quantified as the amount of REM sleep at birth relative to adult REM sleep levels [7]. In all mammal studies to date, the observation that the amount of REM (active) sleep is initially much higher during early postnatal development than it is in later adult life may suggest that REM sleep provides an endogenous source of activation, which may be critical for neurodevelopment. Recent studies performed in rat pups support this hypothesis. In active or REM sleep, muscle twitches are highly structured and induce specific cortical activity during periods of twitching [11•, 12]. Although twitches have long been considered by-products of a dreaming brain, more recent results indicate that twitches are organized behaviors that are functionally meaningful for the developing nervous system [12].

\section{Sleep Regulation}

The regulatory mechanisms governing sleep timing, duration, and intensity result from the interaction of an internal 24-h clock-like circadian process and a sleep-wake-dependent homeostatic process [13]. The homeostatic process reflects an increase in sleep pressure with time spent awake and a decrease with time spent asleep. Assessing sleep under varying homeostatic loads by gradually increasing wakefulness has improved our knowledge of sleep regulation in adults, e.g., $[14,15]$. These studies make a strong case for sleep depth to be reflected in sleep SWA. Accordingly, SWA has been proposed to directly reflect the restorative processes occurring during sleep and, in particular, the dynamics of synaptic strength [16].

The exact age at which sleep deprivation in humans results in a SWA increase is unknown. Yet, a SWA decline across the night is first visible during the second postnatal month [17] and may also be reflected in a decline of theta power observed between 6 and 9 months of age [18]. Another homeostatic marker, the slope of slow waves, shows a sleep-dependent decline as early as 2 months of age [19•]. Sleep homeostasis further develops in adolescence, as reflected in the attenuation of the buildup of sleep pressure across the day with no corresponding change in its decline during sleep [20].

The homeostatic regulation of sleep is developed by P24 in rats, as shown in a maximum of SWA at light onset and a reduction thereafter [21]. Also, prolonged waking elicits an increase in SWA in rats by this age, while younger rats show a compensatory increase in sleep duration instead of increased SWA [22]. In mice, SWA increases during recovery sleep only after P24, while a decline in SWA across baseline sleep and an increase during waking is already apparent at P19 [23].

The circadian clock assures proper entrainment of behavior and physiology with environmental time. Intrinsically photosensitive retinal ganglion cells transduce light into electrical energy and transfer light/dark signals to the suprachiasmatic nucleus (SCN) via the retinohypothalamic tract [24]. Rods and cones maintain a modulating role onto these ganglion cells through synaptic input [25]. Oscillatory activity of SCN neurons regulate many fundamental physiological processes and behaviors, including sleep and arousal, thermoregulation, feeding, and metabolism.

Circadian timing as measured by dim light melatonin onset (DLMO) and its temporal relationship to sleep show agerelated changes. Toddlers have an earlier DLMO time (19:29h) [26] than 9-12-year-old children (20:28h) and 1316-year-old adolescents (20:41h) [27]. These studies collectively suggest an age-related delay in the timing of the circadian clock between early childhood and adolescence. Later bedtimes observed in adolescence are related to this delay in the timing of melatonin onset [28]. Further, the time interval between DLMO and sleep onset increases from adolescence to adulthood [27, 29]. Finally, it has been suggested that the diurnal sensitivity to light undergoes a developmental change [30]. 
Animals are born with an immature circadian system, which achieves its completion during postnatal development. Despite the presence of endogenous SCN rhythms in the mammalian fetus, newborn animals do not display circadian organization [31]. By about 4 weeks, rats predominantly sleep during the light period [10]. A circadian delay resembling that of human adolescents has been shown in rhesus macaques [32]; however, species with polyphasic sleep experience a phase advance in puberty that is accompanied by an increasing consolidation of sleep and wakefulness bouts [33].

\section{Open Questions}

- What is the physiological substrate of sleep homeostasis? What neuronal changes account for increased consolidation of sleep bouts during development? Are the same mechanisms responsible for findings in adults and children?

- Why is adolescence in polyphasic animal species accompanied by a phase advance in puberty? What is the function of a phase delay during adolescence in humans?

\section{Development of Neural Networks}

\section{Cortical Development}

The main trademark of cortical development is a combination of expansion and regression. The number of synapses in children exceeds adult levels [34], as many more synaptic connections are produced than will finally be retained [35]. Neuronal refinement includes the removal of neurons and synapses that fail to make appropriate connections, which ensures the establishment of proper connectivity [36]. Although such regressive processes are most frequent during brain development in early life, they continue to a lesser extent throughout the first two decades of life.

Synapse formation/elimination occurs throughout life; however, the magnitude of these changes varies across age. Structural and functional imaging measures provide indirect observations of human synapse development in vivo. Magnetic resonance imaging (MRI) has proved valuable for spatially measuring trajectories of gray matter volumes throughout development [37]. Also, high-spatialresolution EEG during sleep has become increasingly relevant in tracking cortical maturation. For example, the topographical distribution of SWA reflects cortical plasticity and is thus a reliable marker for neurodevelopment [38]. Other neurodevelopmental markers during sleep are EEG power and EEG coherence in the SWA frequency range. These measures undergo specific maturational trajectories across development (Fig. 1) [39-41].
The inverted U-shaped trajectory of synaptic density is not unique to humans but can also be observed in other primates [35, 42, 43]. Similarly, in rodents, postnatal electron microscopy, together with volumetric analyses of the frontal cortex, reveals an initial increase of synaptic density and volume during early development (Fig. 1). Two-photon imaging studies in mice show an overproduction of synapses during the initial month that is followed by a net elimination. In adult mice, only a fraction of spines are eliminated and formed in comparison to observations during the initial postnatal weeks [44].

The human cortex matures in a posterior-to-anterior trajectory, as measured with both MRI-derived gray matter volumes [45] and SWA topography assessed with highdensity EEG [38]. Likewise, in other primates, dendrites of prefrontal pyramidal neurons develop later than sensorimotor areas [42]. In rats, the primary motor cortex also matures earlier in comparison to the visual cortex, which receives sensory input only after eye opening after P14 [46].

\section{White Matter Development}

In concert with cortical gray matter growth during childhood, underlying axonal bundles become progressively myelinated (see [47] for quantitative analyses or [48] for a review). In all mammalian species, the formation of myelin sheaths is essential for the propagation and speed of neurotransmission. Oligodendrocytes wrap axons with myelin, consisting of multiple layers of closely opposed glial membranes. This insulation improves the passive flow of electrical current, resulting in up to a 1000 -fold increase in action potential conduction speed.

Growing rapidly throughout early life, myelin is an important contributor to brain connectivity and a cornerstone for cognitive brain maturation [49-51]. However, space and movement constraints with MRI make it a challenge to dissect precise morphological and molecular underpinnings of neurodevelopment. Although fiber architecture is highly heritable and thus programmed [52], recent findings in humans suggest a tight coupling between subcortical fiber plasticity and cortical activity, such that they reciprocally trigger growth and maintenance [53•]. Thus, the cortex matures in concert with subcortical structures, which might require sleep. Indeed, sleep-dependent changes in membrane synthesis, oligodendrocyte proliferation, and myelin growth $[54 \cdot, 55]$ indicate that neuronal activity during sleep could induce myelin growth and enhance functional connectivity in the developing brain [40].

The central nervous system (CNS) in rats and mice is less mature at birth in comparison to that in humans, and it is possible to track white matter development and axonal outgrowth in the rodent CNS already at P1-P3. This age 

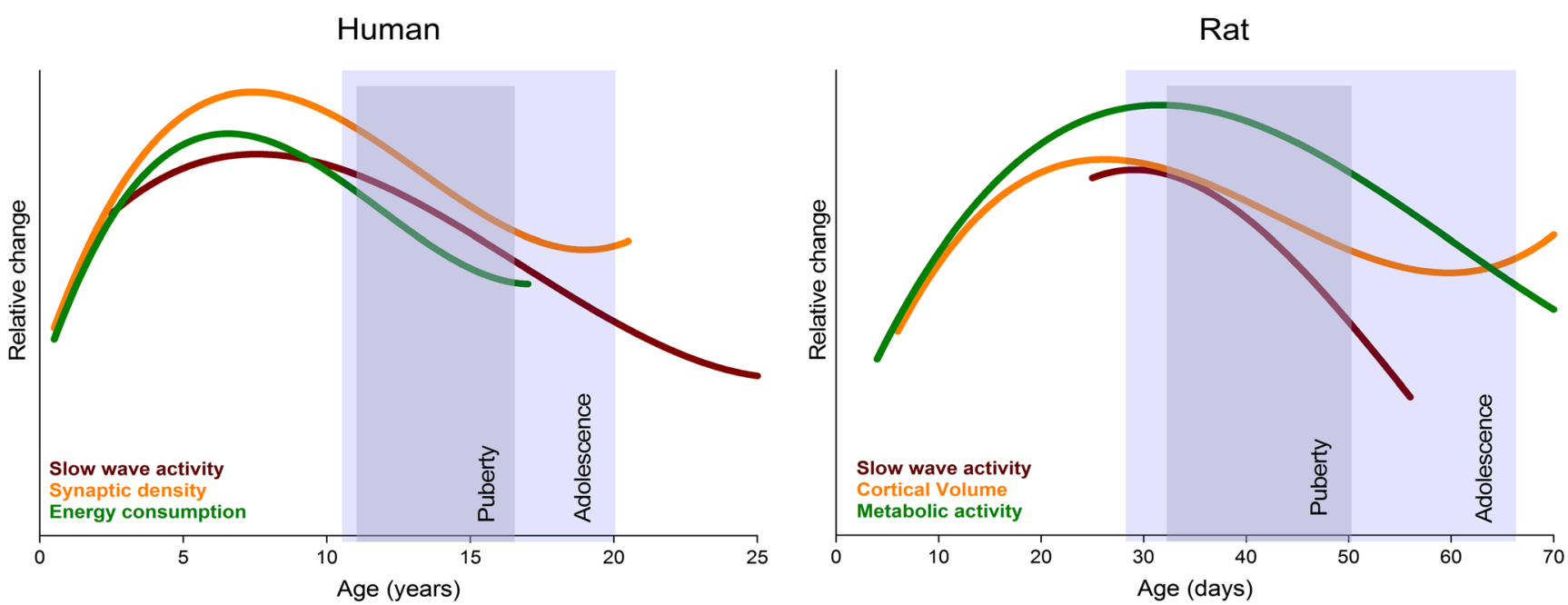

Fig. 1 Time course of sleep and brain maturation variables in humans and rats. Adaptation of a figure in [33] illustrating coincidental transformations across development. Data from [34, 66, 109-112]

corresponds to 32-36 weeks of gestation in human infants [56], while P10 is in terms of white matter development comparable to a term infant [57]. At P10-P14, myelination is well underway and peaks at $\sim \mathrm{P} 20$, when mature oligodendrocyte markers are detectable (e.g., myelin basic protein) [58]. Diffusion tensor imaging (DTI) is a powerful technique for probing the microstructural organization of brain tissue [59]. Consistent with the known timing of myelination in rodents, DTI assessments show prolonged fiber maturation of the corpus callosum as well as the internal and external capsules until at least P40 [60]. White matter changes during adulthood are poorly understood due to a lack of rodent imaging studies from P60 onwards; however, myelination is a universal process that outlasts cortical development. Therefore, gray matter, as well as myelin, is to some degree plastic and might optimize information processing through experience. This is supported by animal studies providing evidence that oligodendrocyte development and myelination are closely linked to neuronal activity [61, 62]. From a mechanistic perspective, the myelin sheath provides metabolic supplies for high neuronal activity and maintenance [63], and neural activity-induced glutamate release along axons seems to trigger myelination [63, 64].

\section{Energy Use During Development}

The maintenance of synapses is an energy-demanding process (for review, see [16]). Thus, neural networks in early life with high-synapse, low-myelin content might have higher energy demands than those of adults, with low-synapse, high-myelin connectivity. Measuring oxygen consumption, which follows a similar developmental time course as synapse density across childhood [65], can assess brain energy use. A comparable pattern is observed for glucose utilization [66] (Fig. 1).
Adenosine triphosphate (ATP) is the molecular currency for intracellular energy transfer. The human cerebral cortex and rat cerebral cortex $[67,68]$ use most ATP for neuronal signaling and providing cellular components. Specifically, action potentials and postsynaptic effects of glutamate require most of the energy, while the resting potential needs a smaller amount of ATP [68]. Developmental changes in cortical energy use are expected to parallel synaptic density alterations throughout development, which experience higher levels during maturation than adulthood. Indeed, correlations between energy use and cortical thickness were reported (for review, see [69]). Strategies to limit high-energy expenditures at excitatory synapses include the initial suppression of NMDA receptor subunits, a process that narrows the synaptic current and thus reduces ATP consumption [70]. The induction of LTP during development further increases energy expenditures, as the insertion of more AMPA receptors into the postsynaptic membrane doubles postsynaptic energy consumption [71]. Another energy-efficient mechanism has been described as synaptic scaling in which neurons homeostatically regulate synaptic signaling to refine cortical circuits [72]. Sleep is increasingly recognized to play an energetically restorative role by lowering the strength of synaptic connections [16].

\section{Open Questions}

- Although cortical and subcortical maturation follows specific spatial trajectories, the functional relevance of these anatomical changes remains understudied. Moreover, increasing evidence suggests microglia to play a crucial role in the elimination of synapses. The potential statedependent role of microglial-dependent synapse elimination during adolescence remains to be examined.

- Sensitive windows for development - when do they start and when do they end? What role does sleep play during 
these periods regarding the impact on later functional and behavioral outcomes?

- Recent research shows maturation-specific maps of how SWA reflects cortical plasticity in children [73•]. However, fundamental questions remain that address how sleep in children affects brain activity and behavior and how developing neural networks drive this relationship [74]. Also, relationships between REM sleep and plasticity during development remain understudied in humans.

- Early sleep problems predict later health outcomes over and above demographic factors. Is inadequate sleep in early life a risk factor for later problems including developmental, behavioral, attentional, and mood disorders? Ethical and feasible sleep interventions using randomized controlled trials are needed in human infants.

- What are the differences and problems when translating findings on cortical function from animals to humans? Cortical development between humans, macaques, and rodents has the caveat that the functional role of sensory systems is species specific. E.g., while the visual system is among the first neuronal networks to mature in humans, rodents open their eyes relatively late in development.

\section{Current Theories of the Function of Sleep: Implications for Cortical Development}

Sleep is ubiquitously found in the animal kingdom, yet its core functions are unknown. Sleep possibly serves various functions, and the proposed hypotheses may be summarized into three main categories: First, sleep serves to reduce energy expenditure; second, sleep is needed for the restoration of key cellular components and macromolecule biosynthesis; and third, sleep facilitates learning and memory by means of improved function based on synaptic plasticity processes [75]. We discuss specific aspects of these theories in the context of neurodevelopmental changes in the subsequent paragraphs.

\section{Sleep Is Important for Balancing Synaptic Strength}

Hypothesis: Sleep renormalizes synaptic strength and shapes plastic brain processes. This synaptic renormalization leads to sleep-dependent improvement of brain functioning and performance [76].

The effects of sleep on performance are conveyed primarily during non-REM sleep. In adults, slow oscillations in particular are thought to be actively involved in cortical plastic processes associated with learning [77•, 78, 79]. During vulnerable periods of life, sleep may be important for plastic processes associated with neurodevelopment (see also the next paragraph). Epidemiological studies show that disturbed sleep throughout preschool and the school age years is associated with psychosocial, somatic, and medical problems [80]. Moreover, sleep problems in childhood predict later psychological and social problems over and above demographic factors [81]. While REM sleep might be of importance for performance benefits during early cortical development [82], SWA during non-REM sleep was suggested to contribute to reorganization processes in synaptic connections at a later age [83]. Human studies concerning the involvement of sleep in neuroplasticity during development, however, remain correlative.

Recent work has shown that caffeine consumption in adolescent rats exerts short-term stimulating effects and can alter the developmental trajectory of SWA [10]. Moreover, caffeine alters behavioral and structural markers of maturation [10]. These caffeine-induced lasting morphological changes might be due to alterations in sleep regulatory processes, such that altering sleep-wake regulation by stimulants like caffeine may affect synaptic plasticity.

\section{Sleep Is Needed for Plasticity}

Hypothesis: Sleep is required to permit plastic processes associated with neurodevelopment [84-86]. Cortical plasticity is hereby understood as the change in synapse number/size or the malleability of existing synaptic connections. The latter in particular involves the neurotransmitter glutamate and its most common docking station, AMPA receptors [87].

It was proposed early on that sleep facilitates brain maturation [3]. An emerging body of literature reports tight associations between sleep and cortical plasticity, thus providing further support for sleep-neurodevelopment links [38, 73•, 88]. Although adult studies reliably link non-REM sleep SWA to functional changes (i.e., learning), results on sleepdependent benefits in children are not consistent [74]. A recent study shows, for instance, that children outperform adults in explicit sleep-dependent sequence learning, which was proposed to reflect developmental refinements of neural networks [89]. Studies in adults have shown that slow-wave deprivation reduces sleep-dependent performance improvements [90, 91], and artificially enhancing slow oscillations results in sleepdependent memory benefits [77•, 79]. During development, SWA maps maturational differences in underlying cortical structure [73•]. Together, these data indicate a relationship between deep sleep slow waves and plastic changes.

In vivo experiments in mice allow for the quantification of cortical plasticity in relation to sleep or wakefulness. In adolescent mice, synaptic remodeling is state dependent: While a gain in cortical spines prevailed during waking, spine loss was larger during sleep, resulting in a negative spine balance at this developmental stage $[92,93]$. Importantly, this spine elimination was only found during development, while no sleepwake-dependent net changes of spine density were observed 
in adult mice. These findings confirm that in adolescent mice, a few hours of sleep and wake affect the density of cortical synapses while after adolescence primarily changes in synaptic strength rather than number can be observed. As shown in adult rats, an overall synaptic balance is preserved [94]. Recent research shows that specific burst firing, the characteristic firing pattern of sleep slow oscillations [95], can impact the functional change of glutamatergic synapses [96•]. Induced burst firing in pyramidal neurons (cortical slices) eliminates AMPA receptors and induces input-specific long-term depression because neuronal plasticity represents a continuum from malleability of existing synapses to structural plasticity, including synapse formation and elimination [97], the impact of SWA on synaptic plasticity may ultimately result in changes in cortical connectivity.

Sleep Increases the Interstitial Space Thereby Reducing Neurotoxic Waste

Hypothesis: Sleep has a critical function in ensuring metabolic homeostasis by removing potentially neurotoxic waste products that accumulate in the awake brain [98]. A recent study found that the cortical interstitial space increases by more than $60 \%$ during sleep, resulting in a striking rise in the convective exchange of cerebrospinal fluid and interstitial fluid, as well as in the clearance of $\beta$-amyloid and other compounds [98].

As already mentioned, sleep is proposed to serve a function opposing wakefulness, i.e., to maintain homeostasis in relation to energy expenditure, restoration of key cellular components, or plasticity [75]. Recent findings point to a more specific functional process. While neurotoxic waste products accumulate during wakefulness, an increase of cortical interstitial space was observed during sleep. This resulted in a striking increase in the convective exchange between cerebrospinal fluid and interstitial fluid, leading to metabolite clearance [98]. These findings in adult mice may be even more important during development when energy consumption is increased, and the accumulation of neurotoxic products is conceivably higher. Thus, it might be of interest to explore the effect of sleep on interstitial space during a period with maximal synaptic density and energy expenditure.

Brain levels of $\beta$-amyloid can be determined as production and clearance rates in humans [99]. Although there is no human evidence showing that sleep helps restore the brain by flushing neurotoxic waste products, the interstitial concentration of $\beta$-amyloid is higher in awake than in sleeping humans similar to rodents [100]. A relevant outlook involves the relationship between $\beta$ amyloid and sleep in neurological disorders like Alzheimer's disease, where understanding the mechanisms of activation of metabolite clearance is critical for treatment development.

\section{What Can Go Wrong? Sleep Disturbances and Development}

Sleep disturbance in early life predicts later cognitive, attentional, and psychosocial problems [80]. Not enough sleep in infants and children is associated with overweight/obesity and lower cognitive performance $[101,102]$, and sleep fragmentation increases the risk of asthma [103]. Sleep disorders are commonly comorbid with psychiatric conditions in children and adolescents [104], including attention deficit hyperactivity disorder, anxiety, depression, and autism spectrum disorders [105]. Regulatory problems during infancy (excessive crying, sleeping or feeding problems) are associated with behavior problems in childhood [106], including adaptive behavior and social skills [107].

Evidence from animal studies shows that sleep is required for neurodevelopmental processes in specific brain circuits during critical periods of life [85, 86, 108•]. Ocular dominance experiments in cats show that during the critical period of visual development, cortical plasticity is enhanced during sleep but not during wakefulness. Moreover, cortical remodeling triggered by monocular deprivation was associated with the amount of non-REM sleep. In reverse, blocking sodium channels and thus neuronal activity during sleep reduced plasticity [84, 85]. These experiments show that during critical periods of development, the maturation of skills not only requires cortical activity during waking but also subsequent sleep. Other studies reported a function of REM sleep for synaptic plasticity of the visual cortex during critical periods [108•]. Additionally, a recent study experimentally altered a neural circuit in the early life of flies, which led to immediate sleep loss and later dysfunction in courtship behavior [86]. This study provided the first evidence that sleep loss during early sensitive periods of life negatively affects species survival.

\section{Conclusion}

Sleep is a basic biological process that undergoes dramatic changes during development. Insufficient sleep in early human life predicts concurrent and future health consequences, such as mood disorders, cognitive problems, and obesity. Animal research provides mechanistic evidence for the role of sleep in neuronal plasticity. Although the link between sleep and neurodevelopmental processes is increasingly recognized, one major challenge remains in the translation of findings from animal research to humans. Further research should consider experimental and longitudinal designs across the life span in humans. 


\section{Compliance with Ethics Guidelines}

Conflict of Interest Salome Kurth, Nadja Olini, Reto Huber, and Monique LeBourgeois declare that they have no conflict of interest.

Human and Animal Rights and Informed Consent This article contains studies with human and animal subjects performed by the authors. All studies were lawfully performed according to the Declaration of Helsinki, approval by institutional ethics committee, and written informed consent from parents or participants. Animal protocols followed the National Institutes of Health Guide for the Care and Use of Laboratory Animals and facilities, and were approved by the Cantonal Veterinary Office of Zurich. Details can be found in the individual studies as cited.

\section{References}

Papers of particular interest, published recently, have been highlighted as:

- Of importance

1. Lamblin MD, Andre M, Challamel MJ, Curzi-Dascalova L, D'Allest AM, De Giovanni E, et al. Electroencephalography of the premature and term newborn. Maturational aspects and glossary. Neurophysiol Clin - Clin Neurophysiol. 1999;29(2):123-219. Electroencephalographie du nouveau-ne premature et a terme. Aspects maturatifs et glossaire. fre.

2. Louis J, Cannard C, Bastuji H, Challamel MJ. Sleep ontogenesis revisited: a longitudinal 24-h home polygraphic study on 15 normal infants during the first two years of life. Sleep. 1997;20(5):323-33.

3. Roffwarg HP, Muzio JN, Dement WC. Ontogenetic development of the human sleep-dream cycle. Science. 1966;152(3722):604-19.

4. Khazipov R, Esclapez M, Caillard O, Bernard C, Khalilov I, Tyzio $\mathrm{R}$, et al. Early development of neuronal activity in the primate hippocampus in utero. J Neurosci: Off $\mathrm{J}$ Soc Neurosci. 2001;21(24):9770-81.

5. Khazipov R, Sirota A, Leinekugel X, Holmes GL, Ben-Ari Y, Buzsaki G. Early motor activity drives spindle bursts in the developing somatosensory cortex. Nature. 2004;432(7018):758-61.

6. Romijn HJ, Hofman MA, Gramsbergen A. At what age is the developing cerebral cortex of the rat comparable to that of the full-term newborn human baby? Early Hum Dev. 1991;26(1):61-7.

7. Jouvet-Mounier D, Astic L, Lacote D. Ontogenesis of the states of sleep in rat, cat, and guinea pig during the first postnatal month. Dev Psychobiol. 1970;2(4):216-39.

8. Galland BC, Taylor BJ, Elder DE, Herbison P. Normal sleep patterns in infants and children: a systematic review of observational studies. Sleep Med Rev. 2012;16(3):213-22.

9. Mirmiran M, van den Dungen H, Uylings HB. Sleep patterns during rearing under different environmental conditions in juvenile rats. Brain Res. 1982;233(2):287-98.

10. Olini N, Kurth S, Huber R. The effects of caffeine on sleep and maturational markers in the rat. PLoS One. 2013;8(9):e72539.

11. Tiriac A, Uitermarkt BD, Fanning AS, Sokoloff G, Blumberg MS. Rapid whisker movements in sleeping newborn rats. Curr Biol. 2012;22(21):2075-80. Data from this study show that during active (REM) sleep, infant rats exhibit highly structured whisker twitching, which induces specific cortical activity. This study contributes to our understanding about interactions between peripheral sensory activity and somatosensory integration during period of neural network development.

12. Blumberg MS, Coleman CM, Gerth AI, McMurray B. Spatiotemporal structure of REM sleep twitching reveals developmental origins of motor synergies. Curr Biol. 2013;23(21):2100-9.

13. Borbely AA, Achermann P. Sleep homeostasis and models of sleep regulation. In: Kryger MH, Roth T, Dement WC, editors. Principles and practice of sleep medicine. Philadelphia: Elsevier Saunders; 2005. p. 405-17.

14. Dijk DJ, Beersma DG, Daan S. EEG power density during nap sleep: reflection of an hourglass measuring the duration of prior wakefulness. J Biol Rhythms. 1987;2(3):207-19.

15. Webb WB, Agnew Jr HW. Sleep cycling within twenty-four hour periods. J Exp Psychol. 1967;74(2):158-60.

16. Tononi G, Cirelli C. Sleep function and synaptic homeostasis. Sleep Med Rev. 2006;10(1):49-62.

17. Bes F, Schulz H, Navelet Y, Salzarulo P. The distribution of slowwave sleep across the night: a comparison for infants, children, and adults. Sleep. 1991;14(1):5-12.

18. Jenni OG, Borbely AA, Achermann P. Development of the nocturnal sleep electroencephalogram in human infants. Am J Physiol Regul Integr Comp Physiol. 2004;286(3):R528-38.

19. Fattinger S, Jenni OG, Schmitt B, Achermann P, Huber R. Overnight changes in the slope of sleep slow waves during infancy. Sleep. 2014;37(2):245-53. This was the first longitudinal investigation of the slope of sleep slow waves as an early marker for the maturation of sleep homeostasis in infants. The results show that the slope increases across age and decreases across a night of sleep, with topographical differences. These data provided evidence for maturational and regional aspects of sleep homeostasis development in infants.

20. Jenni OG, Achermann P, Carskadon MA. Homeostatic sleep regulation in adolescents. Sleep. 2005;28(11):1446-54.

21. Frank MG, Heller HC. Development of diurnal organization of EEG slow-wave activity and slow-wave sleep in the rat. Am J Physiol. 1997;273(2 Pt 2):R472-8.

22. Frank MG, Morrissette R, Heller HC. Effects of sleep deprivation in neonatal rats. Am J Physiol. 1998;275(1 Pt 2):R148-57.

23. Nelson AB, Faraguna U, Zoltan JT, Tononi G, Cirelli C. Sleep patterns and homeostatic mechanisms in adolescent mice. Brain Sci. 2013;3(1):318-43.

24. Berson DM, Dunn FA, Takao M. Phototransduction by retinal ganglion cells that set the circadian clock. Science. 2002;295(5557):1070-3.

25. Wong KY, Dunn FA, Graham DM, Berson DM. Synaptic influences on rat ganglion-cell photoreceptors. J Physiol. 2007;582(Pt 1):279-96.

26. LeBourgeois MK, Carskadon MA, Akacem LD, Simpkin CT, Wright Jr KP, Achermann P, et al. Circadian phase and its relationship to nighttime sleep in toddlers. J Biol Rhythms. 2013;28(5):322-31.

27. Crowley SJ, Acebo C, Fallone G, Carskadon MA. Estimating dim light melatonin onset (DLMO) phase in adolescents using summer or school-year sleep/wake schedules. Sleep. 2006;29(12):163241.

28. Carskadon MA, Acebo C, Jenni OG. Regulation of adolescent sleep: implications for behavior. Ann N Y Acad Sci. 2004;1021: 276-91.

29. Wright Jr KP, Gronfier C, Duffy JF, Czeisler CA. Intrinsic period and light intensity determine the phase relationship between melatonin and sleep in humans. J Biol Rhythms. 2005;20(2):168-77.

30. Carskadon MA, Acebo C, Arnedt JT. Failure to identify pubertally-mediated melatonin sensitivity to light in adolescents. Sleep. 2002;25:A191-A. English. 
31. Reppert SM, Weaver DR, Rivkees SA. Maternal communication of circadian phase to the developing mammal. Psychoneuroendocrinology. 1988;13(1-2):63-78.

32. Golub MS, Takeuchi PT, Keen CL, Hendrickx AG, Gershwin ME. Activity and attention in zinc-deprived adolescent monkeys. Am J Clin Nutr. 1996;64(6):908-15.

33. Hagenauer MH, Lee TM. Adolescent sleep patterns in humans and laboratory animals. Horm Behav. 2013;64(2):270-9.

34. Huttenlocher PR, Dabholkar AS. Regional differences in synaptogenesis in human cerebral cortex. J Comp Neurol. 1997;387(2): 167-78. eng.

35. Rakic P, Bourgeois JP, Eckenhoff MF, Zecevic N, Goldmanrakic PS. Concurrent overproduction of synapses in diverse regions of the primate cerebral-cortex. Science. 1986;232(4747):232-5. English.

36. Rakic P, Bourgeois JP, Goldman-Rakic PS. Synaptic development of the cerebral cortex: implications for learning, memory, and mental illness. Prog Brain Res. 1994;102:227-43.

37. Lenroot RK, Giedd JN. Brain development in children and adolescents: insights from anatomical magnetic resonance imaging. Neurosci Biobehav Rev. 2006;30(6):718-29.

38. Kurth S, Ringli M, Geiger A, LeBourgeois M, Jenni OG, Huber R. Mapping of cortical activity in the first two decades of life: a highdensity sleep electroencephalogram study. J Neurosci: Off J Soc Neurosci. 2010;30(40):13211-9.

39. Feinberg I, Campbell IG. Sleep EEG changes during adolescence: an index of a fundamental brain reorganization. Brain Cogn. 2010;72(1):56-65.

40. Kurth S, Achermann P, Rusterholz T, Lebourgeois MK. Development of brain EEG connectivity across early childhood: does sleep play a role? Brain Sci. 2013;3(4):1445-60.

41. Tarokh L, Carskadon MA, Achermann P. Developmental changes in brain connectivity assessed using the sleep EEG. Neuroscience. 2010;171(2):622-34.

42. Bianchi S, Stimpson CD, Duka T, Larsen MD, Janssen WG, Collins Z, et al. Synaptogenesis and development of pyramidal neuron dendritic morphology in the chimpanzee neocortex resembles humans. Proc Natl Acad Sci U S A. 2013;110 Suppl 2:10395-401.

43. Liu X, Somel M, Tang L, Yan Z, Jiang X, Guo S, et al. Extension of cortical synaptic development distinguishes humans from chimpanzees and macaques. Genome Res. 2012;22(4):611-22.

44. Zuo Y, Lin A, Chang P, Gan WB. Development of long-term dendritic spine stability in diverse regions of cerebral cortex. Neuron. 2005;46(2):181-9.

45. Shaw P, Kabani NJ, Lerch JP, Eckstrand K, Lenroot R, Gogtay N, et al. Neurodevelopmental trajectories of the human cerebral cortex. J Neurosci: Off J Soc Neurosci. 2008;28(14):3586-94.

46. Johns JM, Means LW, Means MJ, McMillen BA. Prenatal exposure to cocaine. I: effects on gestation, development, and activity in Sprague-Dawley rats. Neurotoxicol Teratol. 1992;14(5):337-42.

47. Deoni SC, Dean 3rd DC, O'Muircheartaigh J, Dirks H, Jerskey BA. Investigating white matter development in infancy and early childhood using myelin water faction and relaxation time mapping. Neuroimage. 2012;63(3):1038-53.

48. Paus T, Collins DL, Evans AC, Leonard G, Pike B, Zijdenbos A. Maturation of white matter in the human brain: a review of magnetic resonance studies. Brain Res Bull. 2001;54(3):255-66.

49. Casey BJ, Tottenham N, Liston C, Durston S. Imaging the developing brain: what have we learned about cognitive development? Trends Cogn Sci. 2005;9(3):104-10.

50. Fields RD. White matter in learning, cognition and psychiatric disorders. Trends Neurosci. 2008;31(7):361-70.

51. Johnson MH, Munakata Y. Processes of change in brain and cognitive development. Trends Cogn Sci. 2005;9(3):152-8.
52. Chiang MC, Barysheva M, Shattuck DW, Lee AD, Madsen SK, Avedissian C, et al. Genetics of brain fiber architecture and intellectual performance. J Neurosci: Off J Soc Neurosci. 2009;29(7): 2212-24.

53. Alcauter S, Lin W, Smith JK, Short SJ, Goldman BD, Reznick JS, et al. Development of thalamocortical connectivity during infancy and its cognitive correlations. J Neurosci: Off J Soc Neurosci. 2014;34(27):9067-75. Using longitudinal resting state fMRI and cognitive data in a large human pediatric sample, the authors were able to characterize the functional development of thalamocortical connectivity. These data provide new insights into the tight coupling between subcortical fibers and cortical maturation.

54. Bellesi M, Pfister-Genskow M, Maret S, Keles S, Tononi G, Cirelli C. Effects of sleep and wake on oligodendrocytes and their precursors. J Neurosci: Off J Soc Neurosci. 2013;33(36):14288-300. Using translating ribosome affinity purification combined with microarray analysis in mice, this research shows sleep-specific proliferation of oligodendrocyte precursor cells and phospholipid synthesis. Implications are that the mechanisms associated with myelination may preferentially occur during sleep.

55. Cirelli C. A molecular window on sleep: changes in gene expression between sleep and wakefulness. Neuroscientist : Rev J Bringing Neurobiol, Neurol Psychiatry. 2005;11(1):63-74. eng.

56. Craig A, Ling Luo N, Beardsley DJ, Wingate-Pearse N, Walker DW, Hohimer AR, et al. Quantitative analysis of perinatal rodent oligodendrocyte lineage progression and its correlation with human. Exp Neurol. 2003;181(2):231-40.

57. Hagberg H, Ichord R, Palmer C, Yager JY, Vannucci SJ. Animal models of developmental brain injury: relevance to human disease. A summary of the panel discussion from the Third Hershey Conference on Developmental Cerebral Blood Flow and Metabolism. Dev Neurosci. 2002;24(5):364-6.

58. Wiggins RC. Myelination: a critical stage in development. Neurotoxicology. 1986;7(2):103-20.

59. Mori S, Zhang J. Principles of diffusion tensor imaging and its applications to basic neuroscience research. Neuron. 2006;51(5): 527-39.

60. Baloch S, Verma R, Huang H, Khurd P, Clark S, Yarowsky P, et al. Quantification of brain maturation and growth patterns in C57BL/ $6 \mathrm{~J}$ mice via computational neuroanatomy of diffusion tensor images. Cereb Cortex. 2009;19(3):675-87.

61. Fields RD. Imaging learning: the search for a memory trace. Neuroscientist : Rev J Bringing Neurobiol Neurol Psychiatry. 2011;17(2):185-96.

62. Stevens B, Porta S, Haak LL, Gallo V, Fields RD. Adenosine: a neuron-glial transmitter promoting myelination in the CNS in response to action potentials. Neuron. 2002;36(5):855-68.

63. Lee Y, Morrison BM, Li Y, Lengacher S, Farah MH, Hoffman PN, et al. Oligodendroglia metabolically support axons and contribute to neurodegeneration. Nature. 2012;487(7408):443-8.

64. Kukley M, Capetillo-Zarate E, Dietrich D. Vesicular glutamate release from axons in white matter. Nat Neurosci. 2007;10(3): 311-20.

65. Kety SS. Human cerebral blood flow and oxygen consumption as related to aging. Res Publ Assoc Res Nerv Ment Dis. 1956;35:3145.

66. Chugani HT. A critical period of brain development: studies of cerebral glucose utilization with PET. Prev Med. 1998;27(2):184 8.

67. Lennie P. The cost of cortical computation. Curr Biol. 2003;13(6): 493-7.

68. Attwell D, Laughlin SB. An energy budget for signaling in the grey matter of the brain. J Cereb Blood Flow Metab. 2001;21(10): $1133-45$. 
69. Harris JJ, Reynell C, Attwell D. The physiology of developmental changes in BOLD functional imaging signals. Dev Cogn Neurosci. 2011;1(3):199-216.

70. Hestrin S. Developmental regulation of NMDA receptor-mediated synaptic currents at a central synapse. Nature. 1992;357(6380): 686-9.

71. Wieraszko A. Changes in the hippocampal slices energy metabolism following stimulation and long-term potentiation of Schaffer collaterals-pyramidal cell synapses tested with the 2-deoxyglucose technique. Brain Res. 1982;237(2):449-57.

72. Turrigiano G. Too many cooks? Intrinsic and synaptic homeostatic mechanisms in cortical circuit refinement. Annu Rev Neurosci. 2011;34:89-103.

73. Wilhelm I, Kurth S, Ringli M, Mouthon AL, Buchmann A, Geiger A, et al. Sleep slow-wave activity reveals developmental changes in experience-dependent plasticity. J Neurosci: Off J Soc Neurosci. 2014;34(37):12568-75. This study reports a local increase of sleep SWA after visuomotor adaptation, which is higher in children than adults, and provides gray matter volume correlates. This study is relevant to sleep-learning relationships and their mapping during sensitive windows of brain development.

74. Huber R, Born J. Sleep, synaptic connectivity, and hippocampal memory during early development. Trends Cogn Sci. 2014;18(3): $141-52$

75. Mignot E. Why we sleep: the temporal organization of recovery. PLoS Biol. 2008;6(4):e106.

76. Tononi G, Cirelli C. Sleep and the price of plasticity: from synaptic and cellular homeostasis to memory consolidation and integration. Neuron. 2014;81(1):12-34.

77. Ngo HV, Martinetz T, Born J, Molle M. Auditory closed-loop stimulation of the sleep slow oscillation enhances memory. Neuron. 2013;78(3):545-53. A valuable investigation revealing that auditory stimulation in phase with rhythmic occurrence of slow oscillation up states enhances the slow oscillation rhythm, spindle-activity and declarative memory consolidation in adults. This study shows that slow oscillations in particular are involved in cortical plasticity processes associated with learning.

78. Huber R, Ghilardi MF, Massimini M, Tononi G. Local sleep and learning. Nature. 2004;430(6995):78-81.

79. Marshall L, Helgadottir H, Molle M, Born J. Boosting slow oscillations during sleep potentiates memory. Nature. 2006;444(7119):610-3.

80. Simola P, Liukkonen K, Pitkaranta A, Pirinen T, Aronen ET. Psychosocial and somatic outcomes of sleep problems in children: a 4-year follow-up study. Child Care Health Dev. 2014;40(1):60-7

81. Touchette E, Cote SM, Petit D, Liu X, Boivin M, Falissard B, et al. Short nighttime sleep-duration and hyperactivity trajectories in early childhood. Pediatrics. 2009;124(5):e985-93.

82. McDevitt EA, Rowe KM, Brady M, Duggan KA, Mednick SC. The benefit of offline sleep and wake for novel object recognition. Exp Brain Res. 2014;232(5):1487-96.

83. Ringli M, Huber R. Developmental aspects of sleep slow waves: linking sleep, brain maturation and behavior. Prog Brain Res. 2011;193:63-82.

84. Frank MG, Issa NP, Stryker MP. Sleep enhances plasticity in the developing visual cortex. Neuron. 2001;30(1):275-87.

85. Jha SK, Jones BE, Coleman T, Steinmetz N, Law CT, Griffin G, et al. Sleep-dependent plasticity requires cortical activity. J Neurosci: Off J Soc Neurosci. 2005;25(40):9266-74.

86. Kayser MS, Yue Z, Sehgal A. A critical period of sleep for development of courtship circuitry and behavior in Drosophila. Science. 2014;344(6181):269-74. A convincing investigation demonstrating that sleep promotes normal brain development in Drosophila by experimentally hyperactivating a sleep-promoting neural circuit, which led to sleep loss and later deficits in adult behavior.

87. Kessels HW, Malinow R. Synaptic AMPA receptor plasticity and behavior. Neuron. 2009;61(3):340-50.

88. Buchmann A, Ringli M, Kurth S, Schaerer M, Geiger A, Jenni OG, et al. EEG sleep slow-wave activity as a mirror of cortical maturation. Cereb Cortex. 2011;21(3):607-15.

89. Wilhelm I, Rose M, Imhof KI, Rasch B, Buchel C, Born J. The sleeping child outplays the adult's capacity to convert implicit into explicit knowledge. Nat Neurosci. 2013;16(4):391-3.

90. Aeschbach D, Cutler AJ, Ronda JM. A role for non-rapid-eyemovement sleep homeostasis in perceptual learning. J Neurosci: Off J Soc Neurosci. 2008;28(11):2766-72.

91. Landsness EC, Crupi D, Hulse BK, Peterson MJ, Huber R, Ansari $\mathrm{H}$, et al. Sleep-dependent improvement in visuomotor learning: a causal role for slow waves. Sleep. 2009;32(10):1273-84.

92. Maret S, Faraguna U, Nelson AB, Cirelli C, Tononi G. Sleep and waking modulate spine turnover in the adolescent mouse cortex. Nat Neurosci. 2011;14(11):1418-20. This two-photon microscopy study in adolescent mice shows that synaptic strength is modulated by behavioral state, such that waking is associated with a net increase in cortical spines, while sleep is associated with a net spine loss.

93. Yang G, Gan WB. Sleep contributes to dendritic spine formation and elimination in the developing mouse somatosensory cortex. Dev Neurobiol. 2012;72(11):1391-8.

94. Vyazovskiy VV, Cirelli C, Pfister-Genskow M, Faraguna U, Tononi G. Molecular and electrophysiological evidence for net synaptic potentiation in wake and depression in sleep. Nat Neurosci. 2008;11(2):200-8.

95. Steriade M, Contreras D, Curro Dossi R, Nunez A. The slow $(<1 \mathrm{~Hz})$ oscillation in reticular thalamic and thalamocortical neurons: scenario of sleep rhythm generation in interacting thalamic and neocortical networks. J Neurosci: Off J Soc Neurosci. 1993;13(8):3284-99.

96. Lante F, Toledo-Salas JC, Ondrejcak T, Rowan MJ, Ulrich D. Removal of synaptic $\mathrm{Ca}(2)+$-permeable AMPA receptors during sleep. J Neurosci: Off J Soc Neurosci. 2011;31(11):3953-61. This study examined repetitive burst firing, a characteristic action potential discharge mode of layer $V$ pyramidal neurons during slow-wave sleep, which leads to long-term depression and AMPA receptor insertion. These results show that sleep specific neuronal activity can alter synaptic strength.

97. Holtmaat A, Svoboda K. Experience-dependent structural synaptic plasticity in the mammalian brain. Nat Rev Neurosci. 2009;10(9):647-58.

98. Xie L, Kang H, Xu Q, Chen MJ, Liao Y, Thiyagarajan M, et al. Sleep drives metabolite clearance from the adult brain. Science. 2013;342(6156):373-7.

99. Bateman RJ, Munsell LY, Morris JC, Swarm R, Yarasheski KE, Holtzman DM. Human amyloid-beta synthesis and clearance rates as measured in cerebrospinal fluid in vivo. Nat Med. 2006;12(7): 856-61.

100. Kang JE, Lim MM, Bateman RJ, Lee JJ, Smyth LP, Cirrito JR, et al. Amyloid-beta dynamics are regulated by orexin and the sleep-wake cycle. Science. 2009;326(5955):1005-7.

101. Taveras EM, Rifas-Shiman SL, Oken E, Gunderson EP, Gillman MW. Short sleep duration in infancy and risk of childhood overweight. Arch Pediatr Adolesc Med. 2008;162(4):305-11.

102. Touchette E, Petit D, Seguin JR, Boivin M, Tremblay RE, Montplaisir JY. Associations between sleep duration patterns and behavioral/cognitive functioning at school entry. Sleep. 2007;30(9):1213-9.

103. Kozyrskyj AL, Kendall GE, Zubrick SR, Newnham JP, Sly PD. Frequent nocturnal awakening in early life is associated with nonatopic asthma in children. Eur Respir J. 2009;34(6):1288-95. 
104. Tesler N, Gerstenberg M, Huber R. Developmental changes in sleep and their relationships to psychiatric illnesses. Curr Opin Psychiatry. 2013;26(6):572-9.

105. Ivanenko A, Johnson K. Sleep disturbances in children with psychiatric disorders. Semin Pediatr Neurol. 2008;15(2):70-8.

106. Hemmi MH, Wolke D, Schneider S. Associations between problems with crying, sleeping and/or feeding in infancy and long-term behavioural outcomes in childhood: a meta-analysis. Arch Dis Child. 2011;96(7):622-9.

107. Schmid G, Schreier A, Meyer R, Wolke D. A prospective study on the persistence of infant crying, sleeping and feeding problems and preschool behaviour. Acta Paediatr. 2010;99(2):286-90.

108. Shaffery JP, Lopez J, Roffwarg HP. Brain-derived neurotrophic factor (BDNF) reverses the effects of rapid eye movement sleep deprivation (REMSD) on developmentally regulated, long-term potentiation (LTP) in visual cortex slices. Neurosci Lett. 2012;513(1):84-8. In the context of a supportive role of REM sleep for synaptic plasticity in the visual cortex during critical periods of development, this study shows that REM sleep deprivation blocks brain-derived neurotrophic factor (BDNF) expression and the maturation of inhibitory processes in the adolescent visual cortex.

109. Kurth S, Huber R. Sleep slow oscillations and cortical maturation. In: Frank MG, editor. Sleep and brain activity. Elsevier; 2012.

110. Olini N, Huber R. Diurnal changes in electrocorticogram sleep slow-wave activity during development in rats. J Sleep Res. 2014;23(3):261-7.

111. Van Eden CG, Uylings HB. Postnatal volumetric development of the prefrontal cortex in the rat. J Comp Neurol. 1985;241(3):26874.

112. Booth RF, Patel TB, Clark JB. The development of enzymes of energy metabolism in the brain of a precocial (guinea pig) and non-precocial (rat) species. J Neurochem. 1980;34(1):17-25. 